Г. Т. Найданов, И. О. Нагаслаева, А. С. Ташканэ. Изменение численности структуры и использование трудовых ресурсов Республики Бурятия за 2010-2018 годы

УДК 331.5

DOI 10.18101/2304-4446-2019-2-51-57

\title{
ИЗМЕНЕНИЕ ЧИСЛЕННОСТИ, СТРУКТУРЫ И ИСПОЛЬЗОВАНИЕ ТРУДОВЫХ РЕСУРСОВ РЕСПУБЛИКИ БУРЯТИЯ ЗА 2010-2018 ГОДЫ
}

(C) Найданов Гончик Тушинович

кандидат экономических наук, доцент

E-mail: personalbgu@mail.ru

\section{(c) Нагаслаева Ирина Олеговна}

кандидат экономических наук, доцент

E-mail: nio_irina@list.ru

\section{(C) Ташканэ Александр Сергеевич}

старший преподаватель

E-mail: tashkane@mail.ru

Бурятский государственный университет имени Доржи Банзарова

Россия, 670000, г. Улан-Удэ, ул. Смолина, 24a

В статье рассматривается динамика численности и структуры трудовых ресурсов в Республике Бурятия за 2010-2018 гг., приведены определения трудовых ресурсов, их важность в социально-экономическом развитии региона. Сделан анализ изменения структуры трудовых ресурсов и занятости в Республике Бурятия по гендерному признаку, отраслям, формам собственности, семейному положению, возрасту и уровню образования. Рассмотрены вопросы обеспечения экономики Республики Бурятия трудовыми ресурсами в условиях негативных тенденций в сфере демографической ситуации и сложившегося положения дел в области миграции населения региона. В заключении авторы делают выводы касательно некоторых причин сложившейся ситуации и возможных мер со стороны как государственных учреждений, так и общества.

Ключевые слова: трудовые ресурсы; занятость населения; миграция; миграционные потоки; заработная плата; динамика численности населения.

\section{Для цитирования:}

Найданов Г. Т., Нагаслаева И. О., Ташканэ А. С. Изменение численности структуры и использование трудовых ресурсов Республики Бурятия за период 2010-2018 годы // Вестник Бурятского государственного университета. Экономика и менеджмент. 2019. № 2. С. 51-57.

Трудовые ресурсы - важнейший элемент производительных сил. Количественные и качественные факторы трудовых ресурсов выступают одной из главных характеристик социально-экономического развития любого трудового коллектива и оказывают решающее влияние на эффективность экономического роста. При оценке воздействия динамики изменения трудовых ресурсов важное значение имеют не только общая численность, возрастная структура, качество, но и условия использования трудовых ресурсов. По наиболее общему определению трудовые ресурсы представляют собой часть населения, способную участвовать в трудовом процессе по производству товаров и услуг (в соответствии с 
трудовым законодательством). В их состав включают трудоспособное население в возрасте от 15 до 72 лет.

Изменение численности и структуры трудовых ресурсов региона зависит от большого количества факторов. Отношения, складывающиеся на рынке труда, имеют ярко выраженный социально-экономический характер. Они затрагивают насущные потребности большинства населения страны [4, с. 405]. Эффективное использование экономического потенциала региона во многом определяется численностью населения, проживающего на данной территории, и их растущей потребностью. Основой статистического анализа трудового потенциала является показатель трудовых ресурсов, рынка труда, учета занятости и безработицы [1, с. 28]. В Республике Бурятия сокращение численности населения наблюдалось с начала 1990-х до 2007 г., около 80\% потерь населения в эти годы приходилось на миграционный отток. С 2008 г. в Республике Бурятия наблюдается прибыль населения ${ }^{1}$.

Анализ численности рабочей силы республики показывает, что за рассматриваемый период произошли значительные изменения.

Таблица 1

Динамика численности рабочей силы за период 2010-2017 гг., тыс. чел.

\begin{tabular}{|l|c|c|c|c|c|c|c|c|}
\hline \multicolumn{1}{|c|}{ Показатели } & \multicolumn{7}{|c|}{ Годы } \\
\cline { 2 - 9 } & 2010 & 2011 & 2012 & 2013 & 2014 & 2015 & 2016 & 2017 \\
\hline $\begin{array}{l}\text { Численность } \\
\text { рабочей силы }\end{array}$ & 476,1 & 464,4 & 461,7 & 460,4 & 456,3 & 458,2 & 452,0 & 441,3 \\
\hline $\begin{array}{l}\text { Изменение чис- } \\
\text { ленности }\end{array}$ & $+15,1$ & $-12,7$ & $-2,7$ & $-1,3$ & $-4,1$ & $+1,9$ & $-6,4$ & $-3,9$ \\
\hline
\end{tabular}

С января 2017 г. выборочное обследование рабочей силы среди населения проводится в возрасте 15 лет и старше (до 2017 г. - в возрасте 15-72 лет) ${ }^{2}$. Если в 2010 г. численность рабочей силы в республике составляла 476,1 тыс. чел., то в 2017 г. - уже 441,3 тыс. чел. В целом за этот период сокращение рабочей силы составило 28,0 тыс. чел., или $5,88 \%$. Колебания численности рабочей силы во многом определялись изменениями демографической ситуации и миграционными процессами, происходящими в республике. Сальдо миграции остается отрицательным, коэффициент доходности является недостаточным для обеспечения роста рабочей силы в республике.

По прогнозным данным территориального органа Федеральной службы государственной статистики по Республике Бурятия, в 2018 г. количество рабочей силы составило 454,5 тыс. человек, или 46,16 \% общей численности населения

\footnotetext{
${ }^{1}$ Развитие трудовых ресурсов в Республике Бурятия на период 2010-2020 годов: республиканская целевая программа. В ред. Постановления Правительства Республики Бурятия: НГР ru04000201300339 (от 22.04.2013 г. № 207).

${ }^{2}$ Социально-экономическое положение Республики Бурятия: комплексный доклад / Территориальный орган Федеральной службы государственной статистики по Республике Бурятия. Улан-Удэ. 2019 [Электронный ресурс]. URL: http://www.gks.ru/region/docl1181/IssWWW.exe/ Stg/dv00/iv00330r.htm (дата обращения: 10.01.2019).
} 
Г. Т. Найданов, И. О. Нагаслаева, А. С. Ташканэ. Изменение численности структуры и использование трудовых ресурсов Республики Бурятия за 2010-2018 годы

республики ${ }^{1}$. Из них 412,3 тыс. были заняты в экономике республики и 42,2 тыс. человек не имели работы, но находились в активном поиске. Таким образом, уровень занятости населения в возрасте 15 лет и старше составляет 58,3 \%, уровень безработицы - 9,3 \%. Уровень общей безработицы в январе 2019 г. без учета учащихся и студентов дневной формы обучения и пенсионеров оценивался в $8,2 \%$. В государственных учреждениях службы занятости населения на конец января 2019 г. зарегистрированная численность безработных составила 6,2 тыс. человек.

В ходе дальнейшего анализа необходимо дать оценку обеспеченности экономики трудовыми ресурсами. В целом среднегодовая численность занятых в экономике, по данным государственной статистики по Республике Бурятия за период с 2000 по 2005 г., имеет тенденцию снижения с 395,5 тыс. чел. до 386,6, а за период с 2006 по 2012 г. численность занятых увеличивается с 386, 6 тыс. чел. до 419,3 .

Начиная с 2013 г. имеет место умеренная тенденция снижения, численность занятых составила в 2016 г. 391,2 тыс. чел. Максимальная численность занятых в Республике Бурятия в 1990 г. составляла 479,7 тыс. чел. За этот период в целом количество занятых уменьшилось на 88,5 тыс. чел., т. е. на 18,4\%. Изменение численности занятых продолжает происходить по формам собственности. Снижение занятых наблюдается в таких структурах, как государственная и муниципальная, собственность общественных объединений (организаций), смешанная с иностранным участием, смешанная без иностранного участия. Увеличение занятых наблюдается только на предприятиях частной собственности, где удельный вес занятых увеличился с 55,7 до 62\% (с 2010 по 2014 г. соответственно). В структуре занятых значительный удельный вес составляет численность государственных и муниципальных служащих $(32,4 \%)$.

Уровень занятости населения по полу за рассматриваемый период колеблется незначительно от 0,4 до 1,4\% (мужчины и женщины соответственно). За этот период уровень занятости городского населения снизился с 62,7 до 60,8\%, а сельского населения увеличился с 51,7 до 53,0\%. Необходимо отметить значительное изменение уровня занятости по образованию. Если численность занятых с высшим профессиональным образованием увеличилась с 104,2 тыс. чел. в 2010 г. до 133,0 тыс. чел. в 2016 г., то по другим формам образования наблюдается снижение количества занятых. Так, например, численность занятых, имеющих среднее общее образование, сократилась с 86,0 тыс. чел. в 2010 г. до 67,3 тыс. чел. в 2016 г., основное общее - с 27,8 тыс. до 24,1 тыс. человек, количество занятых, которые не имеют основного общего образования, сократилось с 2,1 тыс. до 1,6 тыс. чел. соответственно. Таким образом, в целом в структуре занятых за рассматриваемый период наблюдается качественный рост показателей трудовых ресурсов, что значительно повышает образовательный потенциал производительных сил республики.

\footnotetext{
1 Численность и состав рабочей силы в возрасте 15-72 лет в Республике Бурятия / Территориальный орган Федеральной службы государственной статистики по Республике Бу-

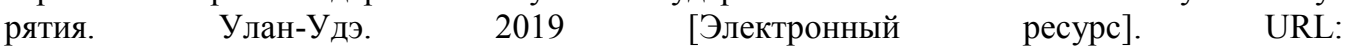
http://burstat.gks.ru/wps/wcm/connect/rosstat_ts/burstat/resources/63a14b804d671a098f2 aff0d534aab22/ors.xls (дата обращения: 10.01.2019).
} 
Краткий анализ уровня занятости населения по возрастным группам показывает, что наблюдается тенденция снижения удельного веса молодых рабочих до 30 лет. Если уровень занятости в возрасте 20-29 лет снизился с 63,9\% в 2010 г. до $60,4 \%$ в 2016 г., то в возрастной группе 15-19 лет удельный вес уменьшился еще больше и составил 4,5\% в 2016 г. против $12,6 \%$ в 2010 г. Процесс снижения удельного веса молодежи способствовал возрастанию численности занятых в возрастных группах 30-39 лет на 0,3\%, 40-49 лет на 2,4\%, 50-59 лет на 1,8\%, 6072 года на $0,7 \%$. Существует тесная взаимосвязь между возрастными группами и стажем работ численности занятых в экономике на последнем месте работы. Численность занятых по стажу работы менее 1 месяца сократился с 9,9 тыс. чел. в 2010 г. до 7,7 тыс. чел в 2016 г., а от 1 месяца до 1 года с 79,1 тыс. чел. до 53,2 тыс. чел. то есть 28,3 и $32,7 \%$ соответственно. Как отмечалось выше, при анализе уровня занятых по возрастным группам снижение удельного веса занятых молодежи способствовало повышению уровня занятых в старших возрастных группах. Так, численность занятых по стажу от 1 года до 3 лет увеличилась с 70,1 тыс. чел. в 2010 г. до 72,1 тыс. чел в 2016 г., от 3 до 5 лет с 58,6 до 60,2 тыс. чел., от 5 до 10 лет с 72,7 до 76,6 тыс. чел и 10 лет и более с 99,3 до 125,2 тыс. человек, то есть на 102,9, 102,7, 106,2 и 126,1\% соответственно.

Эффективность деятельности любого коллектива определяется количеством, качеством и стабильностью трудового коллектива. Социально-экономическая стабильность, как отмечают социологи, во многом определяется семейным положением трудовых ресурсов. Статистические данные по численности занятых в экономике по семейному положению отражают негативные тенденции в развитии демографических процессов. Если численность занятых в 2010 г. составляла 420,8 тыс. чел, то в 2016 г. достигла 408,5 тыс. чел., т. е. уменьшилась на 12,3 тыс. чел. (3\%). Состоящих в браке уменьшилось с 280,2 тыс. чел. в 2010 г. до 276,0 тыс. чел в 2016 г. Также сократилась численность холостых, незамужних на 17,8 тыс. чел (на 20,7\%), вдовцов и вдов на 3,7 тыс. человек (на 19,4\%), а количество разведенных увеличилось на 7,4 тыс. чел., или 117,8\%.

Осуществляя анализ развития трудовых ресурсов, эффективного его использования, невозможно не рассмотреть численность мужчин и женщин, занятых по видам экономической деятельности. Удельный вес мужчин, по данным статистики за 2016 г., составляет 51,7\%, а женщин - 48,3\%. Также значительна доля работающих неформально. По итогам обследований 2016 г., численность занятых в неформальном секторе экономики составила 117,2 тысячи человек [5, с. 153].

В целом разница удельного веса занятых в экономике незначительна. Однако по видам экономической деятельности половая структура занятых различается существенно. Например, численность мужчин преобладает в таких отраслях, как сельское хозяйство, охота и лесное хозяйство $(73,8 \%)$, добыча полезных ископаемых $(87,7 \%)$, обрабатывающее производство $(64,5 \%)$, строительство $(86,2 \%)$, транспорт и связь $(76,2 \%)$ и т. д. Удельный вес женщин в таких отраслях, как оптовая и розничная торговля, ремонт автотранспортных средств, мотоциклов, бытовых изделий и предметов личного пользования, составляет $64,8 \%$, гостиницы и рестораны - 75,7\%, финансовая деятельность - 83,9\%, образование $77,5 \%$, здравоохранение и предоставление социальных услуг - $80,9 \%$ и т. д. 
Г. Т. Найданов, И. О. Нагаслаева, А. С. Ташканэ. Изменение численности структуры и использование трудовых ресурсов Республики Бурятия за 2010-2018 годы

Каковы же основные причины снижения количества трудовых ресурсов? Среди самых явных причин основной остается неудовлетворительное социальноэкономическое положение Республики Бурятия, что особенно заметно после перехода региона из Сибирского федерального округа в Дальневосточный. Средняя зарплата в Республике Бурятия, по данным Бурятстата, составляет 36396 р., в Дальневосточном федеральном округе согласно докладу Национального агентства финансовых исследований - 52759 р. На это влияют и экологические ограничения. Более половины территории Бурятии включено в состав Байкальской природной территории, характеризующейся жесткими условиями природопользования, что оказывает существенное влияние на социально-экономическое развитие региона [6, с. 2].

Следствием сложившейся ситуации в экономике является отрицательное сальдо миграции населения в Республике Бурятия. Отток населения из Бурятии за январь - сентябрь 2018 г. составил 2989 человек. Это выше значения соответствующего периода 2017 г. на 48,2\%. Основная часть мигрантов $(98,5 \%)$ перемещалась в пределах Российской Федерации. Наиболее высокая интенсивность оттока на 1000 населения наблюдалась в Муйском $(-28,6)$ и Северо-Байкальском $(-21,9)$ районах. Данные районы являются самыми северными территориями республики, и к недостаточному уровню доходов там прибавляется общая отсталость инфраструктуры, высокие по сравнению со средними по республике цены и суровые климатические условия. Основной причиной миграционного оттока является выезд населения в более благоприятные климатические зоны России [2, с. 145]. Удельный вес межрегиональной миграции составил 34,5\%. Миграционный отток населения из республики в другие регионы России в сравнении с аналогичным периодом прошлого года вырос на 799 и составил 2587 человек. Жители Бурятии чаще переезжают в регионы Центрального федерального округа 765 человек, в том числе в Москву и Московскую область - 597; в регионы Южного федерального округа - 416, в том числе в Краснодарский край - 261; в регионы Северо-Западного федерального округа - 403, в том числе в СанктПетербург и Ленинградскую область - 327 человек. Отток населения в регионы Сибирского федерального округа составил 551 человек ${ }^{1}$.

В осенний период наблюдается усиление миграции молодежи, выезжающей на обучение в более престижные вузы крупных городов России (Москва, СанктПетербург, Новосибирск, Иркутск, Красноярск, Томск и др.) [3, с. 74]. Вместе с тем усложняет ситуацию то, что за пределы Бурятии уезжают люди, находящиеся в трудоспособном состоянии, но не видящие значимых перспектив на территории родного региона. Некоторая часть уезжает на заработки в Южную Корею, Израиль, Монголию и другие страны. Кто-то из них после получения достаточной суммы денег вернется домой, однако какая-то часть останется за пределами Республики Бурятия. В то же время нельзя не отметить тот факт, что, несмотря на сложную ситуацию, население Республики Бурятия в 2018 г. вырастет, по прогнозным данным территориального органа Федеральной службы государственной статистики по Республике Бурятия, на 377 человек. Это связано с высо-

\footnotetext{
${ }^{1}$ Отток населения из Бурятии вырос почти на 50 процентов // Номер один. 2018. 14 нояб. [Электронный pecypc]. URL: https:/gazeta-n1.ru/news/69349/ (дата обращения: 10.01.2019).
} 
кой рождаемостью в Бурятии, которая тем не менее упала за первое полугодие 2018 г. до 6,8 тыс. детей (уменьшение на 2,5\% по сравнению с аналогичным периодом 2017 г.).

Также следует отметить, что определенное количество молодых жителей Бурятии выезжает за пределы республики с целью получения образования. Поскольку в отчетности учитываются люди старше 15 лет, то отъезд молодежи на обучение в другие регионы России и за рубеж отражается в статистике изменения численности рабочей силы региона. Несомненно, что некоторая часть выехавших за пределы республики с целью получения образования вернется на территорию Бурятии и будет работать здесь. Однако спрогнозировать болееменее точное количество тех, кто вернется, в данный момент времени не представляется возможным.

Таким образом, несмотря на некоторые положительные изменения в качестве рабочей силы в Республике Бурятия (рост уровня образования), в целом перспективы выглядят отнюдь не радужными. После перехода Бурятии в Дальневосточный федеральный округ отсталость республики в уровне экономического развития стала еще более заметной. Так, средняя зарплата в Бурятии составляет $68,98 \%$ от уровня Дальневосточного федерального округа. Несмотря на ожидающиеся положительные изменения, связанные с вхождением Бурятии в ДФО, ожидать значительного улучшения в ближайшее время не приходится. Это значит, что трудоспособное население республики будет все так же искать любую возможность заработка, в том числе и за пределами Бурятии.

\section{Литература}

1. Будажанаева Д. Ц.-Д. Статистический анализ трудового потенциала Республики Бурятия // Экономический анализ: теория и практика. 2010. № 32 (197). С. 27-33.

2. Бурдуковский Р. П. Исследование миграционного оттока населения в Республике Бурятия // Общество: политика, экономика, право. 2014. № 1. С. 142-146.

3. Бурдуковский Р. П. Сравнительный анализ миграционных процессов Республики Бурятия в условиях несбалансированности рынка труда // Известия Дальневосточного федерального университета. Экономика и управление. 2013. № 3 (67). С. 68-78.

4. Горчак М. О. Современное состояние рынка труда и уровень занятости на примере Республики Бурятия // Экономика и социум. 2016. № 11 (30). С. 405-408.

5. Занданова О. Ф., Жданова Е. М. О проблемах рынка труда и занятости в Республике Бурятии // Молодой ученый. 2017. № 50. С. 150-154.

6. Хохлова О. А. Методология статистического исследования экономики региона: автореф. дис. ... д-ра экон. наук. М., 2007. С. 2. 
Г. Т. Найданов, И. О. Нагаслаева, А. С. Ташканэ. Изменение численности структуры и использование трудовых ресурсов Республики Бурятия за 2010-2018 годы

\section{CHANGES IN LABOR FORCE PARTICIPATION, COMPOSITION AND UTILIZATION IN THE REPUBLIC OF BURYATIA FOR THE PERIOD 2010-2018}

Gonchik T. Naydanov

Cand. Sci. (Econ.), A/Prof.

E-mail: personalbgu@mail.ru

Irina O. Nagaslaeva

Cand. Sci. (Econ.), A/Prof.

E-mail: nio_irina@list.ru

Aleksandr S. Tashkane

Senior Lecturer

E-mail: tashkane@mail.ru

Dorzhi Banzarov Buryat State University

24a Smolina St., Ulan-Ude 670000

The article deals with the dynamics of labor force and composition of labor resources in the Republic of Buryatia for 2010-2018. We have defined labor resources, emphasized their significance for socio-economic development of the region. The analysis of changes in the composition of labor resources and employment in the Republic of Buryatia by gender, job sector, ownership, family status, age and education level was carried out. We have considered the problems of providing the economy of the republic with human resources in the context of negative trends in the current demographic situation and migration outflow from the region. Finally, the article reveals the contributing factors to the current situation and the possible measures of both the government agencies and the society that can change it.

Keywords: labor resources; employment of population; migration; migration flows; salaries and wages; population dynamics. 